Uit het archief van AVRUG-Bulletin 'Kongo. Een schoolvoorbeeld van kolonialisme'.

Een interview van 30 juni 1980 van W. Blondeel, V. Foutry en F. Van Mensel met Prof. Dr. A.A.J. VAn BILSEN, RUG

Traduit des archives de AVRUG-Bulletin

'Congo. Un exemple type de colonialisme'.

Un entretien du 30 juin 1980 de

W.Blondeel, V.Foutry et F.Van Mensel avec Prof. Dr. A.A.J. VAN BILSEN, RUG, 
Met dank aan de Afrika Vereniging van de Rijksuniversiteit Gent (AVRUG)

Avec les remerciements à l'Association Afrique de l'Université de Gand (AVRUG) 


\title{
SUMMARY
}

\section{CONGO. A CLASSIC EXAMPLE OF COLONIALISM}

\author{
A REPRINT OF A 1980 INTERVIEW WITH \\ PROF. DR. A.A.J. VAN BILSEN
}

This is a reprint, accompanied by a French translation, of an interview with Jef Van Bilsen (1913-1996), the former Belgian adviser to the first Congolese President, Joseph Kasavubu. The interview was conducted when Van Bilsen was a professor at the University of Ghent. Van Bilsen is questioned about his 'Thirty Years Plan' to prepare the Belgian Congo for independence. The plan, published in 1955, provoked strong criticism in the Belgian political and academic establishment because at that time decolonisation was not accepted on the political agenda, at least not within thirty years. Van Bilsen describes the narrow minded and extreme paternalistic vision of the Belgian colonial administration and the awakening of Congolese nationalism. The consequence of this cramped policy is that in 1960 Belgium grants independence to the Congo in a reaction of panic and in a completely unprepared way. Furthermore, Van Bilsen relates, as a privileged witness, the disastrous outcome of foreign interference in the struggle between President Kasavubu, Prime Minister Lumumba and the Katangese secessionist, Tshombe. He cites his statement to Tshombe that Lumumba could not be seen as a communist and reports how he advocated a compromise between the three opponents. 
Afrika Focus, Vol. 16, Nr. 1-2, 2000, pp. 1-33.

AVRUG-Bulletin, jg. 7, nr. 3-4 september-december, 1980, pp.2334 .

\title{
KONGO
}

\section{schoolvoorbeeld van kolonialisme}

\section{0}

\section{Een gesprek op 30 juni 1980 van W. Blondeel, V. Foutry en F. Van Mensel met:}

\author{
Prof. dr. A.A.J. VAN BILSEN, R.U.G.
}

Eind 1955 publiceert $U$ uw 'Dertiqjarenplan voor de politieke ontvoogding van Belgisch-Afrika'. De indruk is dat die ontvoogdingsgedachte opeens uit de lucht komt gevallen. Kunt $U$ de achtergronden en ontstaansgeschiedenis ervan belichten?

"In de loop van de Belgische koloniale geschiedenis zijn er wel geïsoleerde en principiële stemmen opgegaan tegen de kolonisatie als zodanig. Zij gingen meestal uit van meer links opgestelde elementen in de B.W.P. [Belgische Werklieden Partij] - later B.S.P. [Belgische Socialistische Partij] - en van uiterst links. 
Afrika Focus, Vol. 16, Nr. 1-2, 2000, pp.1-33.

\title{
CONGO
}

\section{Un exemple type de colonialisme}

\section{0}

\author{
Un entretien du 30 juin 1980 de W.Blondeel, \\ v. Foutry et F.Van Mensel avec : \\ Prof. Dr. A.A.J. VAN BILSEN, R.U.G.
}

Traduit du néerlandais par D. Godfroid, G. de Villers et D. Beke

Octobre 2000

Fin 1955 vous avez publié «un plan de trente ans pour l'émancipation politique de l'Afrique belge. Cela donne l'impression que cette idée de décolonisation tombait tout à coup du ciel. Pouvez-vous en éclaircir l'arrière-plan et l'émergence?

«Tout au long de l'histoire coloniale belge, des voix isolées mais fortes, se sont élevées contre cette colonisation. Elles émanaient le plus souvent de la gauche du POB [Parti Ouvrier Belge], qui deviendra le PSB [Parti Socialiste Belge] ainsi que de l'extrême gauche. 
In de brede publieke opinie, in de traditionele partijen, in het 'establishment' werd soms gereageerd tegen

misbruiken of wantoestanden of kwam men op voor verbetering van het koloniaal stelsel. Niet voor dekolonisatie, zeker niet op korte of middellange termijn.

Er heerste integendeel in België een gelukzalige, zelfingenomen overtuiging dat óns kolonisatiemodel tevens het beste was, de fouten van anderen vermeed, en dat het nog eeuwen zou stand houden."

\section{Beschermde informatie}

"Die mentaliteit ging gepaard met kritiekloze verheerlijking van Leopold II en de eigen koloniale verwezenlijkingen, een zorgvuldig beschermde 'informatie' over wat in Belgisch-Kongo omging, een feitelijke controle op nagenoeg alle in de kolonie werkzame blanken via de overheid, de veiligheidsdiensten, de machtige werkgevers, de missiestructuur en de onderlinge gebondenheid van 'de 3 machten': Bestuur, Missie en Bedrijfsleven. Het was schier onmogelijk vrij te publiceren of te spreken.

Ik heb raderwerken van deze geleide en gecontroleerde informatie kunnen nagaan toen ik in 1946 en 1947'als onafhankelijk persman - vertegenwoordiger van het persagentschap Belga - in Kongo werkzaam was. Ik mocht wel met iedereen vrij contact opnemen, maar wanneer ik een bericht doorstuurde dat voor de overheid wat gevoelig lag, kwam het terug uit Brussel en werd de informant op de vingers getikt. Voor informatie was ik aangewezen op wat het Gouvernement-Generaal en de koloniale ondernemingen kwijt wilden. Met de inheemsen was het contact moeilijk omdat ik de taal niet sprak. De enkele ontwikkelden of half-ontwikkelden bij wie taalbarrière niet bestond, lagen dan op een andere manier aan banden: zij behoorden op hun beurt tot het personeel van een koloniale matschappij, waren ondergeschikte staatsagenten, maakten deel uit van de missiestructuren... De enige vrije mensen waren de nietgesubsidieerde protestanten."

\section{Isolement en vervreemding}

"Daar komt nog bij dat de inheemse bevolking geen intellectuele elite bezat die voor haar kon spreken - het begin van een eerste universiteit dateert van 1952 - en dat zij niet vrij kon reizen in het binnenland en tot de 
Dans l'ensemble de l'opinion publique, dans les partis traditionnels, dans 'l'establishment', on réagissait parfois contre des abus ou des situations intolérables, et on pouvait se prononcer pour une amélioration du système colonial. Mais on n'appelait pas à la décolonisation, certainement pas à court ou à moyen terme.

On avait en Belgique la confortable et prétentieuse conviction d'avoir développé une colonisation modèle ; on pensait avoir évité les erreurs commises par d'autres, et que cela pourrait durer encore des siècles. »

\section{Information protégée}

«Cette mentalité s'alliait à une glorification sans critique de Léopold II et des réalisations coloniales de la Belgique, ce qui entrainait une 'information'

soigneusement protégée sur ce qui se passait au Congo belge et un contrôle de fait sur tous les blancs travaillant dans la colonie, contrôle exercé par l'administration, par les services de sécurité, par les grands employeurs, par les structures missionnaires, et par l'emprise conjuguée des trois pouvoirs : l'Administration, les Missions, les Entreprises. Il était presque impossible de publier ou de parler ouvertement.

J'ai pu pénétrer les rouages de ce système d'information orientée et contrôlée lorsqu'en 1946 et 1947 je travaillais au Congo comme reporter-indépendant représentant l'agence de presse Belga. Je pouvais librement contacter tout le monde, mais quand je transmettais une information délicate pour les autorités, Bruxelles la renvoyait et l'informateur était rappelé à l'ordre. Pour des informations, je devais me contenter de ce que le Gouvernement Général et les entreprises coloniales voulaient bien divulguer. . Le contact avec les autochtones était difficile car je ne parlais pas la langue. Les quelques évolués ou demi-évolués avec lesquels la barrière linguistique n'existait pas, étaient bridés de façon différente : soit ils appartenaient au personnel d'une société coloniale, soit ils étaient des agents d'Etat subordonnés, soit ils faisaient partie des missions. Seuls les protestants sans subsides étaient des gens libres. »

\section{Isolement et aliénation}

«Il faut ajouter que la population indigène n'avait pas d'élites intellectuelles qui puissent parler en son nom - la première université datant de 1952 -, qu'elle ne pouvait pas se déplacer librement dans le pays et que jusque dans les années '50 elle ne pouvait venir en Belgique ni voyager à l'étranger. Les premiers étudiants noirs sont arrivés en 
vijftiger jaren ook niet naar België kon komen, laat staan naar het buitenland. De eerste zwarte studenten zijn pas in 1954 naar België gekomen en niet eens naar de universiteit maar op uitnodiging van de Kristelijke syndicale beweging naar de Sociale School te Heverlee.

Dergelijk beleid isoleerde Kongo en de Kongolese bevolking, maakte iedere poging tot vrije informatiestroming met de buitenwereld onmogelijk en vervreemdde in hoge mate de Belgische politieke klasse en de publieke opinie van wat in Kongo omging.

De weinigen die zich in België wél met koloniale informatie bezighielden zaten ook weer in zo'n koloniaal verband: missionarissen op rust, gepensioneerde ambtenaren met gewoonlijk een tweede carrière in een koloniaal bedrijf ...

Wanneer dan een enkele kritische stem opging vond deze noch in de publieke opinie, noch bij enige politieke drukkingsgroep of instelling gehoor.

Het zijn overigens twee oud-kolonialen, beide lid van de Koloniale Raad te Brussel - het wetgevend organisme - nl. A. Marzorati ${ }^{1}$, gewezen vice-gouverneur-generaäl voor Ruanda-Urundi, later hoogleraar aan de U.L.B. [Université Libre de Bruxelles], B.S.P.-lid en bewonderaar van de Britse Fabian Society, en J. Van Wing ${ }^{2}$ die van 1911 tot na W.O. II als missionaris op het terrein werkzaam was geweest, die mij aangespoord hebben te schrijven en te spreken om te trachten dat 'gordijn' rondom Kongo en het Kongobeleid te doorbreken."

\section{Officiële doctrine}

"Zo is dan bij mij de idee ontstaan me professioneel naar het hoger onderwijs - en de vrijheid van spreken en schrijven die het waarborgt te oriënteren. Ik werd parttime benoemd aan het Universitair Instituut voor de Overzeese Gebieden te Antwerpen, waar koloniaal overheidspersoneel werd geschoold. Men heeft mij daar later willen

\footnotetext{
'MARZORATI, Alfred (1881 1955) : Dr. in de rechten U.L.B. Koloniale carrière in Belgisch-Kongo en Ruanda-Urundi.(1912-1930). Gouverneur van Ruanda-Urundi met de rang van vice-gouverneur-generaal (19261930). Prof. aan de U.L.B. (1931-1951) en de Rijkshandelshogeschool van Antwerpen (1933-1951). Lid van de Koloniale Raad (1946-1955).

2 VAN WING, Jozef, s.j. (1844-1970: Koloniale carrière (1911-1945). Missionaris en later regionaal superieur van Belgisch Kongo en Ruanda-Urundi. Lid van de Koloniale Raad (1946-1960). Lector aan de U.C.L. en prof. aan het Koloniaal Instituut te Antwerpen.
} 
Belgique en 1954, non pas à l'université mais à l'Ecole Sociale de Heverlee, à la suite d'une invitation du Mouvement Syndical Chrétien.

Une telle politique isolait le Congo et la population congolaise, ce qui rendait impossible toute tentative pour informer le monde extérieur, et ce qui rendait dans une large mesure la classe politique ainsi que l'opinion publique belges étrangères à ce qui se passait au Congo.

Le peu de gens qui en Belgique s'occupaient d'informer sur la colonie étaient liés au système colonial : c'étaient des missionnaires retraités ou des fonctionnaires pensionnés exerçant généralement une seconde carrière dans une entreprise coloniale. Lorsqu'une voix critique s'élevait, elle n'attirait l'attention ni de l'opinion publique, ni d'un groupe de pression politique, ni de quelque institution.

Ce sont cependant deux anciens coloniaux, tous deux membres du Conseil Colonial à Bruxelles - organe législatif de la colonie, qui m'ont stimulé à écrire et à parler afin d'essayer de rompre le 'mur de silence' autour du Congo et autour de la politique congolaise. Il s'agit de : A. Marzorati ${ }^{1}$ ancien vice-gouverneur général du RwandaUrundi, ensuite professeur à l'ULB [Université Libre de Bruxelles], membre du PSB et admirateur de la Fabian Society en Grande Bretagne, et de J. Van Wing ${ }^{2}$ qui de 1911 jusqu'après la seconde guerre mondiale a mené une vie fort active au Congo en tant que missionnaire.»

\section{Doctrine officielle}

«L'idée m'est venue ainsi de m'orienter professionnellement vers l'enseignement supérieur, qui garantit la liberté de s'exprimer et d'écrire. Je fus nommé à mi-temps à l'Institut universitaire des Territoires d'Outre Mer à Anvers, qui formait le personnel de la fonction publique. Plus tard, on a voulu me renvoyer parce que, comme il était

\footnotetext{
${ }^{1}$ MARZORATI, Alfred (1881-1955): docteur en droit à l'U.L.B. [Université Libre de Bruxelles]. Carrière coloniale au Congo Belge et au Rwanda-Urundi (1912-1930). Gouverneur du Rwanda, titre de vice-gouverneur général (1926-1930). Professeur à l'U.L.B. (1931-1951) ainsi qu'à l'Ecole Commerciale Supérieure d'Anvers (1933-1951). Membre du Conseil Colonial (1946-1955).

${ }^{2}$ VAN WING, Jozef, s.j. (1844-1970) : carrière coloniale (1911-1945). Missionnaire et plus tard supérieur régional du Congo belge et du Rwanda-Urundi. Membre du Conseil colonial (1946-1960). Lecteur à l'U.C.L. [Université Catholique de Louvain] et professeur à l'Institut Colonial à Anvers.
} 
buitenzetten omdat, en dat is de officiële, schriftelijke motivering, 'omdat ik afweek van de officiële doctrine ...!' En dat in een instelling die bij wet universitair werd genoemd.

Ik heb daar gedoceerd van 1950 tot 1960, dus tijdens de jaren van strijd rondom het dekolonisatievraagstuk.

Om nu terug te komen op uw vraag naar de achtergronden van het 'Dertigjarenplan', dat is gegroeid, enerzijds uit de analyse van de naoorlogse wereldsituatie en de nieuwe beginselen aanvaard door de internationale Gemeenschap (het V.N. -handvest) en anderzijds uit een consequent doortrekken van de elementen van kritiek op het Belgisch koloniaal

beleid door 'reformisten' als P. Rijckmans, J. Van Wing, A. Marzorati en vele anderen."

Wat wilde $U$ bereiken ?

"Ideaal gezien, dat het Belgisch Parlement een werkgroep zou oprichten, bestaande uit parlementsleden en buitenstaanders, met als opdracht een nieuw koloniaal beleid - in mijn opvatting een dekolonisatiebeleid - voor te stellen.

Model daarvoor stonden talrijke Britse parlementaire commissies wier conclusies steeds onder de vorm van 'witboeken' werden gepubliceerd en ruim verspreid, of ook nog het door het Belgisch Parlement opgerichte Studiecentrum voor de Vlaams-Waalse vraagstukken, waarvan ik een tijdlang lid was geweest in de jaren 1949-51."

\section{Marginaliteit}

"Toen bleek dat regering en parlement geen belangstelling hadden voor mijn - aanvankelijk in het Nederlands gestelde geschriften - ben ik ook in het Frans gaan publiceren en heb ik getracht de publieke opinie te bereiken. Dat bleef echter bij talloze spreekbeurten voor meestal marginale groepen. Daarbij dient ook 'La Relève' vermeld, een klein groepje, dat een weekblad uitgaf, maar met jonge mensen die tot de politiek-intellectuele bourgeoisie behoorden en in de kabinetten zaten. Zij hadden dus wel degelijk een invloedssfeer.

Veel werd ik niet gehoord of gelezen, tot plots een titel', een 'Dertigjarenplan' fascinerend werkte... Dan is er een jarenlange polemiek gekomen. De teksten begonnen langzaam 
précisé noir sur blanc dans la motivation, 'je m'écartais de la doctrine officielle...! Et cela dans une institution dont la loi avait fait un institut universitaire. J'y ai enseigné de 1950 à 1960, donc dans des années où la problématique de la décolonisation était un sujet d'affrontements.

J'en viens à votre question concernant le passé du Plan de Trente Ans : celui-ci a germé dans mon esprit à partir, d'une part, d'analyses de la situation mondiale dans l'après-guerre, et des nouveaux principes acceptés par la communauté internationale (la Charte des Nations Unies), à partir d'autre part, du souci de tirer de façon conséquente les conclusions des éléments d'une critique de la politique coloniale belge que l'on trouvait chez des 'réformistes', tels que P. Ryckmans, J. Van Wing, A. Marzorati et beaucoup d'autres. »

Quel but vouliez-vous atteindre?

«L'idéal était que le parlement belge fonde un groupe de travail composé de membres du parlement et de personnalités indépendantes chargés de présenter une nouvelle politique coloniale - qui devait être, de mon point de vue, une politique de décolonisation.

Les nombreuses commissions parlementaires britanniques pouvaient être données en exemple. Leurs conclusions étaient publiées sous forme de livres blancs et largement distribuées. Le Centre d'Etudes pour les problèmes flamands - wallons, créé par le Parlement belge (dont je fus membre de 1949 à 1951) constituait un autre exemple. »

\section{Marginalité}

«Lorsqu'il s'est avéré que le gouvernement et le parlement ne s'intéressaient pas à mes écrits, qui étaient rédigés en néerlandais, j'ai également publié en français et j'ai essayé de toucher l'opinion publique. J'ai donné de nombreuses conférences, mais le plus souvent, pour des groupes marginaux. Je dois citer aussi "La Relève", un hebdomadaire publié par une petite équipe de jeunes gens, appartenant à la bourgeoisie politico-intellectuelle et qui siégeaient dans les cabinets. Ils exerçaient donc une certaine influence.

On ne m'écoutait pas beaucoup et on ne lisait presque pas mes articles jusqu'à ce qu'un titre 'Plan de Trente Ans' captive soudain l'attention... Une polémique de plusieurs années s'en est suivie. Les textes pénétraient petit à petit au Congo, et en 1956, l'intérêt 
door te sijpelen naar Kongo en in 1956 is er een spontane belangstelling ontstaan in kringen van jonge Kongolezen omheen 'Conscience Africaine', 'Abako' [Association des Bakongo], e.a.

Uit deze en andere contacten is dan een zeer actieve Afrikaans-Belgische studiegroep ontstaan, die we na Marzorati's dood in 1955 MARZORATI-groep hebben genoemd."

Hoe was de groep samengesteld?

"Dat waren ongeveer evenveel Afrikanen als Belgen. De Belgen behoorden tot alle politieke strekkingen, gaande van dr. J. Spaey ${ }^{3}$ van 'La Relève' tot Ernest Glinne, toen vrijgestelde van het A.B.V.V. maar de meesten kwamen toch uit progressieve groepen behorend tot de 'Kristen familie' zoals Pax Christi of de groep rond 'De Maand'. Van Afrikaanse zijde sloten nagenoeg alle studenten uit Kongo en Ruanda-Urundi, die toen voor het eerst haar België mochten komen, bij ons aan. Dat waren er een vijftiental."

Bereikte U ook studenten aan de U.L.B. [Université Libre de Bruxelles]?

"Ja, natuurlijk. Bomboko5, Mandi ${ }^{6}$ uit Kongo, Ngirumpatse en Rwubuzizi uit Ruanda-Urundi bijvoorbeeld. Er waren er ook uit Luik en uit niet-universitaire instellingen ..."

\footnotetext{
${ }^{3}$ SPAEY, J.: Dr. in de geneeskunde. Kabinetschef van de minister' van Volksgezondheid (1948), later Secretaris-Generaal van de Nationale Raad voor Wetenschapsbeleid.

${ }^{3}$ VAN WING, Jozef, s.j. (1844-1970: Koloniale carrière (1911-1945). Missionaris en later regionaal superieur van Belgisch Kongo en Ruanda-Urundi. Lid van de Koloniale Raad (1946-1960). Lector aan de U.C.L. en prof. aan het Koloniaal Instituut te Antwerpen.

4 GLINNE, Ernest : Lid van het Europees parlement, diende in 1966 als socialistisch kamerlid een wetsvoorstel tegen rassenhat en uiting van racisme in. Dit voorstel ligt momenteel weer ter tafel (De Morgen, 11.10 .1980$, p. 4).

${ }^{5}$ вомВоко, Lokumba (voorheen Justin Bomboko) : In 1960 kamerlid voor de Union Mongo. Minister van Buitenlandse Zaken in de regering Lumumba. Voorzitter College van Commissarissen 1960-61. Diverse ministerposten tot 1969. Gearresteerd in 1971 maar later in ere hersteld. Thans [1980] zakenman te Kinshasa.

${ }^{6}$ MANDI, André : Student U.L.B. op het einde van de jaren '50. Later ambassadeur, o.a. in Rome.
} 
pour ces débats s'est affirmé spontanément dans des cercles de jeunes Congolais autour en particulier de "Conscience Africaine" et de "l'Abako" [Association des Bakongo].

A partir de ces contacts et d'autres est né un groupe d'étude africano-belge très actif. Après la mort de Marzorati, survenue en 1955, nous l'avons appelé le groupe MARZORATI. »

Comment ce groupe était-il composé?

« Il comptait à peu près autant d'Africains que de Belges. Ces derniers appartenaient à tous les partis politiques, dans un éventail allant du dr. J. Spaey ${ }^{3}$ de "La Relève" jusqu'à Ernest Glinne ${ }^{4}$, à l'époque délégué de la FGTB [Fédération Générale des Travailleurs de Belgique]. La plupart cependant faisaient partie de groupes progressistes appartenant à la 'Famille Chrétienne' comme Pax Christi ou 'De Maand'. Du côté africain quasi tous les étudiants qui, venant du Congo et du Rwanda-Urundi, avaient été autorisés pour la première fois à venir en Belgique, se sont joints à nous. Ils étaient une quinzaine. "

Avez-vous également touché des étudiants de l'ULB [Université Libre de Bruxelles]?

« Bien sûr : Bomboko ${ }^{5}$ et Mandi ${ }^{6}$ du Congo, Ngirumpatse et Rwubuzizi du RwandaUrundi, par exemple. Il y en avait aussi de Liège ainsi que d'autres institutions nonuniversitaires. »

\footnotetext{
${ }^{3}$ SPAEY, J. docteur en médecine. Chef de cabinet du ministre de la santé (1948), ensuite Secrétaire Général du Conseil National pour les 'Affaires Scientifiques'

${ }^{4}$ GLINNE, Ernest : membre du Parlement européen, a déposé en 1966 en tant que membre socialiste de la Chambre une proposition de loi contre la haine raciale et les répressions de racisme. Cette proposition fut en 1980 remise sur le tapis (De Morgen, 11/10/1980 page 4).

${ }^{5}$ BOMBOKO, Lokumba (Justin) : En 1960, parlementaire pour l'Union mongo. Ministre des Affaires étrangères du gouvernement Lumumba. Président du Collège des Commissaires (1960-1961). Divers postes de ministre jusqu'en 1969. Il a été arrêté en 1971, mais réhabilité ensuite. Actuellement [en 1980] homme d'affaires à Kinshasa.
}

${ }^{6}$ MANDI, André : étudiant à l'U.L.B. jusque fin 1950. Ensuite ambassadeur, e.a. à Rome. 


\title{
Subversief
}

\author{
Mochten zij vrij circuleren ?
}

"Jawel, maar zij maakten vaak hun beklag over de politie. Niet altijd terecht misschien. Maar ik denk wel dat zij geplaagd werden. Met kleinigheden eigenlijk: verklikkers die voor $50 \mathrm{fr}$. overbriefden dat die of die 'subversieve kranten' las. Sommigen werden daar werkelijk door geterroriseerd ...

Maar, om op de MARZORATI-groep terug te komen : we hadden ook nauwe contacten met 'Présence Africaine' en andere groepen uit Frans- en Brits-Afrika, waarvan we bij gelegenheid vertegenwoordigers op bezoek kregen, o.m. Alioune Diop ${ }^{7}$ uit Senegal en André Rabemananjara ${ }^{8}$ uit Madagascar, na de nationalistische opstand in 1947 ter dood veroordeeld, dan verbannen naar Parijs en later minister van Buitenlandse Zaken van Madagascar."

\section{Historisch kader}

"Onze vergaderingen vonden plaats in de historische afspanning 'De Zwaan' op de Grote Markt. Dat was toen nog geen luxe-restaurant voor overvoede zakenlieden maar een oud-Brusselse herberg waar alles nog herinnerde aan de 19de eeuw toen de B.W.P. [Belgische Werklieden Partij] er werd opgericht of, nog vroeger, toen Karl Marx en andere bannelingen er werkten.

We hadden ook een permanent secretariaat in de Parochianenstraat en vonden, merkwaardig genoeg, enige financiële overlevingssteun bij lieden met een hoger inkomen, verlichte zakenlieden en, uitzonderlijk, zelfs mensen uit de koloniale wereld..."

Welke waren de hoofdpunten van uw 'Dertigjarenplan' ?

"Intellectueel begaafde mensen vormen, een begin maken met verantwoordelijke instellingen én medezeggenschap, een beroep doen op de Verenigde Naties om de nieuwe politiek

\footnotetext{
7 DIOP, Alioune : Dakar, Senegal. Hoofdredacteur van het gezaghebbend tijdschrift Présence Africaine (Dakar en Paris).

${ }^{8}$ RABEMANANJARA, Jacques : Uit Madagascar. Ter dood veroordeeld na de nationalistische opstand van 1947. Later verbannen naar Parijs. Later minister van Buitenlandse Zaken. Gekend Afrikaans dichter.
} 


\section{$\underline{\text { Subversif }}$}

Pouvaient-ils circuler librement?

« Oui, mais ils se plaignaient régulièrement de la police. A tort parfois. Mais je crois qu'on les tracassait pour des bagatelles : des dénonciateurs, pour $50 \mathrm{Fr}$., rapportaient que tel ou tel lisait des journaux subversifs. Certains d'entre eux étaient réellement terrorisés par cette surveillance.

Pour en revenir au groupe MARZORATI, nous avions également des contacts étroits avec "Présence africaine" et aussi avec des groupes franco- ou anglo-africains dont les représentants nous rendaient visite à l'occasion : ainsi, Alioune Diop ${ }^{7}$ du Sénégal et André Rabemananjara ${ }^{8}$ de Madagascar. Ce dernier, après la révolte nationaliste de 1947 a été condamné à mort, puis exilé à Paris ; plus tard, il est devenu ministre des Affaires étrangères de Madagascar. "

\section{Cadre historique}

« Nos réunions se tenaient dans le cadre historique 'La Maison du Cygne' à la Grand' Place. Ce n'était pas encore à l'époque un restaurant luxueux pour d'opulents hommes d'affaires, mais un vieux bistrot bruxellois qui évoquait le $19^{\text {eme }}$ siècle, quand le POB y a été fondé ou que Karl Marx et d'autres bannis venaient y travailler.

Nous avions également un secrétariat permanent dans la 'rue des Paroissiens'. Ce qui est assez étrange c'est que nous trouvions un certain soutien financier auprès de gens bénéficiant de revenus élevés, d'hommes d'affaires éclairés et exceptionnellement même de gens du monde colonial...»

Quels étaient les points principaux de votre plan «Plan de Trente Ans»?

«Former des gens intellectuellement doués, mettre en place de premières institutions responsables assurant une participation [des Congolais], faire appel aux Nations Unies

\footnotetext{
${ }^{7}$ DIOP, Alioune : Dakar, Sénégal. Rédacteur en chef de l'importante revue 'Présence africaine' (Dakar et Paris).

${ }^{8}$ RABEMANANJARA, Jacques : Madagascar. Condamné à mort après la révolution nationaliste de 1947. Ensuite exilé à Paris. Plus tard, ministre des Affaires étrangères. Poète africain connu.
} 
geloofwaardig te maken en tenslotte - en dat is dan heel belangrijk geworden - een timing invoeren.

Voor een belangrijke en getimede dekolonisatie waren in die jaren toch heel wat aanknopingspunten: de Britse politiek in Maleisië; de dekolonisatie van de Filippijnen op 30 jaar. In de opeenvolgende grondwetten van de landen die onafhankelijk werden, was ook een interessante evolutie te zien met telkens wat meer stemrecht wat meer bevoegdheid en verantwoordelijkheid, grotere medezeggenschap van de bevolking."

Was het in 1954-55 niet wat laat voor een dekolonisatieplan op dertig jaar?

"Objectief -en achteraf - gezien was het vanzelfsprekend te laat. In 1954 dacht ik echter helemaal niet dat de dekolonisatie zes jaar later een voldongen feit zou zijn. Er ligt tussen 1954 en 1960, of juister: tussen 1958 en 1960 een enorme stroomversnelling."

\section{Achterstand}

"Daar moet ik aan toevoegen dat de termijn van dertig jaar een tactisch aspect had; vermits ongeveer niemand de idee van dekolonisatie op middellange termijn kon aanvaarden en gezien de achterstand van Kongo maakte een langere termijn het voorstel meer geloofwaardig.

Ik hoopte dat deze termijn redelijk zou klinken en aldus een aantal vooroordelen zou wegruimen, zodat onmiddellijk een plan kon worden uitgewerkt met de medewerking van Kongolezen."

Hoe bedoelt $U$ die 'achterstand van Kongo' ?

"Voor mij is Kongo het schoolvoorbeeld van kolonialisme, d.i. van een beleid, van buiten af opgelegd, dat de belangen van het 'moederland' 'dient' en waar de ontwikkeling in de hoogste mate in functie staat van deze belangen.

Kongo beschikte - vooral na W.O. II - over een betere economische en sociale infrastructuur dan vergelijkbare kolonies en de mise en valeur was er veel intenser dan elders. Maar het is voor mij eveneens duidelijk dat de 
pour donner du crédit à cette nouvelle politique et finalement - ceci est également très important- introduire un timing.

Dans l'optique d'une décolonisation conséquente et programmée, on avait à l'époque diverses sources d'inspiration : la politique britannique en Malaisie, la décolonisation, en trente ans, des Philippines. Dans les constitutions successives des pays qui accédaient à l'indépendance, on remarquait une évolution intéressante : il y avait à chaque fois un peu plus de droit de vote, un peu plus de compétence et de responsabilité, ainsi qu'une plus grande participation de la population. »

\section{Est-ce qu'il n'était pas un peu trop tard en 1954-1955 pour envisager une} décolonisation en trente ans?

« En prenant du recul il va de soi qu'il était trop tard. En 1954, je ne pensais pas du tout que la décolonisation serait un fait accompli six ans plus tard. Entre 1954 et 1960 , ou plus exactement entre 1958 et 1960 on a assisté à une forte. »

\section{$\underline{\text { Retard }}$}

« Mais je dois ajouter que le délai de trente ans avait un aspect tactique ; étant donné qu'à peu près personne n'acceptait l'idée d'une décolonisation à moyen terme et étant donné le retard du Congo, un délai plus long rendait la proposition plus crédible.

J'espérais que le délai paraîtrait raisonnable, et que de ce fait certains préjugés disparaîtraient de telle façon qu'on puisse établir immédiatement un plan avec la participation des Congolais. »

Que voulez-vous dire par 'le retard du Congo'?

« Pour moi, le Congo est un exemple type de colonialisme, c'est-à-dire d'une politique imposée de l'extérieur, 'servant' les intérêts de la 'mère patrie', et où le développement du pays est dans une large mesure fonction de ces intérêts.

Le Congo possédait, surtout, après la seconde guerre mondiale, une meilleure infrastructure économique et sociale que certaines colonies comparables et la mise en valeur y était plus intense qu'ailleurs. Mais il était clair pour moi qu'ici encore plus qu'ailleurs l'homme africain, ne comptait qu'en fonction du plan d'exploitation 
Afrikaanse mens er meer nog dan elders slechts telde in functie van het koloniaal exploitatieplan. Aanduidingen hiervoor zijn bij voorbeeld dat het ronselen van arbeidskrachten in ellendige voorwaarden slechts effectief werd geregeld toen de demografische achteruitgang alarmerend werd, en dat de indrukwekkende sociale politiek van vooral de Union Minière rechtstreeks is voortgevloeid uit de groeiende schaarste aan arbeiders en de behoefte aan halfgeschoolden.

Een ander voorbeeld is het onderwijs, dat essentieel beperkt bleef tot het koloniaal behoeftenpeil, rekening houdend met de evangelisatieproblemen van de missies. Zelfs toen er tenslotte toch een universiteit kwam, blééf een van de laatste gouverneurs-generaal pleiten tégen het inrichten van een rechtenfaculteit, want die zou een kweekschool voor politici kunnen worden.

De kolonie werd vrij planmatig ontwikkeld wat productie en evacuatie van die producten betreft en de mens werd ontwikkeld in functie van die, het moederland verrijkende productie.

In andere kolonies werd sedert generaties aan elitevorming gedaan en werden geschoolde inheemsen op verantwoordelijke functies geplaatst. Aldus hadden zij inheemse leiders en woordvoerders, rechters, ambtenaren en officieren.

In Kongo was het daarvoor in 1955 onherroepelijk te laat, hoewel nog vijf kostbare jaren werden verloren..."

In 1955 was het woord 'onafhankelijkheid' nog onbekend. De verklaring van januari 1959 belooft die onafhankelijkheid. Hoe is in die vier jaar de toestand geëvolueerd?

"De eerste nationalistische bewegingen - met Abako voorop zijn in 1956-57 met hun uitbouw begonnen. Tot in '58 was er nog geen fysieke bedreiging voor het Belgisch gezag. Na de EXPO '58 werd de 'Mouvement National Congolais' opgericht en in december namen enkele Kongolezen, waaronder Lumumba deel aan de Conferentie van Accra. In enkele gebieden groeide er spanning en in Beneden-Kongo leidde dat tot een beweging van burgerlijke ongehoorzaamheid, wat sterk indruk maakte op de Koloniale overheid." 
coloniale. Le recrutement d'ouvriers dans des conditions déplorables, par exemple, n'a été sérieusement réglementé qu'à partir du moment où le déclin démographique est devenu alarmant. La politique sociale impressionnante qu'a surtout développé l'Union Minière n'était que la réponse à une pénurie croissante d'ouvriers ainsi qu'au besoin d'ouvriers semi-qualifiés.

Un second exemple est l'enseignement, qui est resté pour l'essentiel conçu en fonction des besoins de la colonie, compte étant tenu des problèmes d'évangélisation des missions. Et quand finalement on a créé une université, un des derniers Gouverneurs Généraux plaidait encore contre la mise en place d'une faculté de droit, parce que celle-ci pourrait devenir une pépinière de politiciens.

La colonie était développée méthodiquement pour la production et l'exportation de cette production, et l'homme était développé en fonction de ces activités enrichissant la mère patrie.

Dans d'autres colonies, on formait des élites depuis plusieurs générations et on donnait des fonctions de responsabilité à des autochtones qualifiés. Ils avaient donc des dirigeants et des porte-parole autochtones, des magistrats, des fonctionnaires et des officiers.

Dès 1955, il était pour cela au Congo irrévocablement trop tard, et cinq années précieuses seront encore perdues...»

En 1955, on ne connaissait pas encore le mot 'indépendance'. La déclaration de janvier 1959 promet cette indépendance. Comment a évolué cette situation en quatre ans?

«Les premiers mouvements nationalistes - avec l'Abako en tête - se sont développés en 1956-1957. Jusqu'en 1958 il n'y avait pas encore de contestation frontale, physique de l'autorité belge. Le Mouvement national congolais a été fondé après l'Expo '58 et en décembre quelques Congolais parmi lesquels Lumumba, ont participé à la Conférence d'Accra. La tension est montée dans certaines régions et s'est traduite dans le BasCongo par un mouvement de désobéissance civile. Cela a fait forte impression sur les autorités coloniales. » 
Toch komt die verklaring van januari 1959 zeer plots. Was daar, objectief gezien, voldoende reden voor?

"Sedert juli 1958 toen gouverneur-generaal Pétillon minister werd van Koloniën was er verandering op komst. Men zag in dat er op één of andere manier moest gedekoloniseerd worden. Bij het Hof, de regering, de hoge koloniale administratie, de koloniale groep van de Société Générale en voor een deel bij de politieke partijen groeide dat inzicht. Alleen was men het er niet over eens hoe ver men juist moest gaan of hoe snel."

\section{Koerswijziging}

"Nagenoeg al deze kringen verwierpen de idee dat een datum het begin van de verandering moest zijn en dat datum en beleid in overleg met de Kongolezen moesten vastgesteld worden. Men was nog lang niet aan een rondetafelconferentie toe.

Tot die koerswijziging had de ExPO '58 in sterke mate bijgedragen. Het contact met bezoekers uit de hele wereld had de hier aanwezige Kongolezen bewuster gemaakt en de gesprekken met die Kongolezen hadden Belgen uit de politieke klasse gesensibiliseerd.

De sprong naar het vastleggen van een beleid was echter groot. Pétillon werd opgevolgd door Van Hemelrijck wiens taak het was de beleidsverklaring tot stand te brengen. De verklaring van januari '59 is moeizaam tot stand gekomen, in nachtelijke discussies; er kwam bijna een scheuring in de regering van. Er werd o.m. lang en fel geruzied over het al dan niet opnemen van het woord 'onafhankelijkheid' in de verklaring ... Tegenover dit voorstel van van Hemelrijck stonden o.a. Wigny, Lilar, en De Vleeshouwer afwijzend. En dan heeft de Koning de verklaring tot zich getrokken, meer gebaseerd op de tekst van Van Hemelrijck, dan op het compromis dat er tenslotte was uitgekomen ...

Met de 'verklaring' zijn we volop in een stroomversnelling beland die precies een jaar later, met de rondetafelconferentie, een hoogtepunt zou krijgen."

In een recente televisie uitzending (RTBF, 30 juni 1980) werd o.a. sterk benadrukt dat de studenten een belangrijke rol zouden gespeeld hebben op de achtergrond van de Rondetafelconferentie. Waren er toen geen wrijvingen tussen 
La déclaration de janvier 1959 survient quand même très soudainement. Objectivement, y avait-il suffisamment de raisons?

«Depuis le mois de juillet 1958, lorsque le Gouverneur Général Pétillon devint ministre des Colonies, des changements étaient en vue. On était conscient que d'une manière ou l'autre, il fallait décoloniser. Cet état d'esprit gagnait du terrain à la Cour, au sein du Gouvernement et de la haute administration coloniale, dans le groupe colonial de la Société Générale et inégalement dans les partis politiques. Seulement on n'était pas d'accord sur la rapidité avec laquelle agir ni sur la question du jusqu'où aller.»

\section{Changement d'orientation}

« Pratiquement tout le monde dans ces milieux rejetait l'idée qu'une date doive être fixée pour le début du changement, et qu'un calendrier et le contenu de la politique soient fixés de commun accord avec les Congolais. On n'en était pas encore à la Conférence de la table ronde.

L'Expo '58 avait largement contribué à un changement d'orientation. Le contact avec des visiteurs du monde entier avait rendu les Congolais plus conscients et les entretiens avec ces Congolais avaient sensibilisé les Belges de la classe politique.

Mais il y avait encore un grand pas à franchir pour concrétiser une nouvelle politique. Van Hemelrijck succéda à Pétillon, avec la tâche d'adopter une déclaration politique. La déclaration de janvier 1959 fut difficile à élaborer. On s'éternisait en discussions nocturnes. Le gouvernement faillit tomber. Il y eut de longues et vives discussions concernant en particulier la mention du mot 'indépendance' dans la déclaration... Wigny, Lilar et De Vleeshouwer étaient contre la proposition de Van Hemelrijck. Ensuite le Roi s'est occupé de cette déclaration, se basant plus sur le texte de Van Hemelrijck que sur le compromis auquel finalement le gouvernement était arrivé...

Avec cette 'déclaration' les évolutions se sont précipitées. C'est précisément un an plus tard, lors de la conférence de la table ronde, que le moment crucial sera atteint. »

Lors d'une émission télévisée (RTBF, le 30 juin 1980) on a insisté sur le fait que les étudiants avaient joué un rôle important dans la conférence de la table ronde. $N^{\prime} y$ 
de mensen die al een hele tijd in België verbleven en de nieuwkomers uit Kongo ?

De studenten werden aanzien als onvolwassen door de politici, die hen 'les enfants', 'les élèves' noemden. Maar zij bezaten een aanzienlijke intellectuele bagage, waren in België 'thuis' en hadden heel wat interessante contacten gelegd. Zo kon Bomboko bij voorbeeld zomaar aanbellen bij Rolin'.

De studenten werden echter wel buiten de eigenlijke conferentie gehouden. Zij waren immers geen officiële afgevaardigden of aldviseurs. Door die noodgedwongen marginaliteit werden mogelijke tegenstellingen dus verzacht: in de ogen van de politieke, leiders bleven zij dus 'op hun plaats'. Maar invloed hadden tij ontegensprekelijk.

De MARZORATI-groep, had gezorgd voor een secretariaat met vergaderzaal voor de Kongolese delegaties en hun raadgevers - ingericht met de steun van Maurits Naessens en de Bank van Parijs en de Nederlanden! - en daar werd met zijn allen, politici, adviseurs, studenten, de tactiek voor de rondetafelconferentie besproken. Daar is ook de idee van een 'Front Commun' ontstaan.

Wat mij betreft, ik heb sterk gepleit voor het Front Commun en voor twee eisen die vóór alles op tafel moesten komen: een statuut voor de Conferentie dat zo dicht mogelijk dat van een constituante moest benaderen en de vaststelling van de datum voor de onafhankelijkheid."

\section{Coup de théâtre}

"De tactiek van het Front-Commun slaagde volkomen. De Belgische regering en de vertegenwoordigers van het Parlement verbonden $\mathrm{zich}$ ertoe de resultaten van de Conferentie om te zetten in wetgevende en uitvoerende teksten en beslissingen.

Het bepalen van de datum werd een 'coup de théâtre'. Zonder verzet, zonder tegenvoorstellen, aanvaardde de Belgische delegatie het meest radicale voorstel: 30 juni 1960, nauwelijks vijf maanden later..."

${ }^{9}$ ROLIN Henri : Minister van State. Hoogleraar aan de U.L.B. Speelde als [socialistisch] senator een belangrijke rol in de R.C. [Ronde Tafelconferentie]. 
avait-il pas à l'époque des conflits entre les gens qui résidaient déjà depuis quelque temps en Belgique et les nouveaux venus du Congo?

« Les politiciens considéraient les étudiants comme immatures, ils les appelaient 'les enfants', 'les élèves'. Mais ceux-ci possédaient un solide bagage intellectuel, se sentaient chez eux en Belgique et avaient noué des contacts intéressants. Bomboko, par exemple, pouvait sonner à la porte de Rolin'.

Les étudiants ne furent cependant pas admis à la conférence même. Ils n'y étaient ni délégués ni conseillers officiels. Grâce à leur marginalisation certains conflits potentiels furent atténués. Aux yeux des leaders politiques, les étudiants étaient ainsi restés 'à leur place'. Mais ils ont eu indiscutablement de l'influence.

Le groupe MARZORATI, avec l'aide de Mauritz Naessens et de la Banque de Paris et des Pays-Bas avait installé un secrétariat et une salle de réunion pour les délégations congolaises et leurs conseillers. C'est là que tous ensemble, politiciens, conseillers, étudiants, discutaient de la tactique à suivre pour la conférence de la table ronde. Et c'est là qu'est née l'idée d'un Front Commun.

En ce qui me concerne, j'ai plaidé pour le Front Commun et pour que deux exigences soient rencontrées en priorité : l'octroi d'un statut pour la Conférence qui se rapprocherait le plus possible de celui d'une assemblée constituante, la fixation de la date de l'indépendance. »

\section{Coup de théâtre}

« La tactique du Front Commun a parfaitement réussi. Le gouvernement belge ainsi que les représentants du Parlement s'engagèrent à transformer les résultats de la conférence en textes législatifs et exécutifs ainsi qu'en décisions.

La fixation de la date fut un coup de théâtre : sans aucune résistance et sans aucune contre-proposition, la délégation belge a accepté la proposition la plus radicale : le 30 juin 1960, à peine cinq mois plus tard...»

\footnotetext{
${ }^{9}$ ROLIN, Henri : Ministre d'Etat. Professeur à l'U.L.B. A joué comme sénateur[socialiste] un rôle important à la T.R. [Table Ronde].
} 
"Mijns inziens stond België voor een drievoudige keuze. Allereerst, het koloniaal regime zonder fundamentele toegevingen voortzetten; een oplossing die kennelijk als onhoudbaar werd afgewezen, mede omdat dit een repressieactie zou gevergd hebben die toen, op het hoogtepunt van de Algerijnse kwestie, onaanvaardbaar was.

Een tweede oplossing was de dekolonisatie onder toezicht en verantwoordelijkheid van de Verenigde Naties laten gebeuren en te onderhandelen over een langere overgangstermijn.

Er waren aanwijzingen dat een overgangstermijn mogelijk was mits België zich verbond tot een vaste en gewaarborgde uiteindelijke datum voor algehele onafhankelijkheid. Dit bleek uit een overleg binnen het Centraal Comité van de Abako - toen de radicaalste partij - in, de herfst van 1959, waaraan ik heb deelgenomen. De Abako was bereid voor een overgangstermijn van vijf jaar te onderhandelen mits het Abako-gebied onmiddellijk interne autonomie verkreeg.

Kasa-Vubu's idee was dat het Abako-gebied autonoom zou worden en de anderen stilaan meer autonomie zouden verkrijgen naarmate zij beschaafd en rijp zouden worden, want zij deelden de anderen in naarmate van beschaafdheid en onbeschaafdheid en zelfs wildheid..."

Zei men dat werkelijk zo ?

"Zo ongeveer, ja. Die wilden, dat waren de Pygmeeën. Maar minder ontwikkeld... ik geloof wel dat dit aan de werkelijkheid beantwoordde... volgens Kasa-Vubu zou het eindpunt dan een federatie van gelijken zijn die België niet meer zou nodig hebben. Nu, dat was een vrij rustige opvatting."

Die gedachte leefde niet meer in 1960 ?

"Nee, intussen was gebleken dat de buitenlandse invloeden, zo groot waren, dat men de staat gecentraliseerd moest houden." 


\section{Pourquoi cette concession surprenante?}

« La Belgique était selon moi placée devant un triple choix. Premièrement, continuer le régime colonial sans concessions fondamentales, solution manifestement intenable et qui a été rejetée. On avait conscience que cela aurait exigé une action de répression qui à l'époque, au point culminant de la question algérienne était devenue inacceptable.

Une deuxième solution était un processus de décolonisation sous la surveillance et la responsabilité des Nations Unies, en négociant une période de transition plus longue.

On avait des indications qu'une période de transition pouvait être acceptée, mais à condition que la Belgique s'engage sur la date de l'indépendance totale et en garantisse le respect. Ceci ressort d'une délibération à laquelle j'ai participé, au sein du Comité Central de l'Abako, qui était à l'automne 1959 le parti le plus radical. L'Abako était prêt à négocier pour une période de transition de cinq ans à condition que la région d'implantation de l'Abako obtienne immédiatement l'autonomie interne.

Kasa-Vubu souhaitait l'autonomie de sa région et que les autres régions obtiennent progressivement plus d'autonomie au fur et à mesure qu'elles deviendraient plus civilisées et plus mûres. En effet il classait les autres régions en fonction de leur degré de civilisation, de barbarie, et même de sauvagerie ...»

\section{Parlait-on effectivement ainsi?}

«Oui à peu près Les sauvages étaient les Pygmées. Dire qu'ils étaient moins évolués, je crois pour ma part que cela correspondait à la réalité. Pour Kasa-Vubu, le but a atteindre était une fédération d'égaux qui n'auraient plus besoin de la Belgique. Il envisageait que les évolutions se dérouleraient de manière paisible. »

\section{Cette idée n'existait plus en 1960 ?}

« Non, entre-temps il s'était avéré que les influences extérieures étaient tellement grandes que l'Etat devait rester centralisé. » 
Waarom heeft België ook deze tweede dekolonisatie-oplossing verworpen ?

"Naar mijn mening zag België noodgedwongen in dat men moest dekolonizeren, maar men wou dat beperken tot de juridische onafhankelijkheid en vermijden dat de Belgische economische belangen in het gedrang kwamen door vreemde invloeden, die via de V.N. onvermijdelijk het land zouden binnenkomen.

Slechts de bezorgdheid om de Belgische economische belangen zoveel mogelijk te vrijwaren en tegelijk de Belgische staat te ontslaan van de mogelijks zware financiële en militaire lasten die de handhaving van de kolonie met zich zou brengen, kan verklaren waarom men tenslotte voor de derde oplossing heeft gekozen: onmiddellijke onafhankelijkheid."

\section{Gok}

"Begin 1960 stond statistisch vast dat $80 \%$ van de stemgerechtigden niet-gepolitiseerde plattelanders waren die naar alle waarschijnlijkheid gematigd zouden stemmen, wat dus zou leiden tot een gematigd parlement en een gematigde regering. Voor een behoorlijke kadervorming ontbrak de tijd, zodat het onafhankelijke Kongo willens nillens zou moeten blijven steunen op het bestaande apparaat Belgische ambtenaren, rechters en officieren.

Terecht - doch naar later zou blijken, overmoedig - noemde de Belgische regering dit beleid 'le pari-congolais', de Kongolese gok.

Men twijfelde er niet aan dat men deze gok zou winnen. Met Belgische troepen in de bases van Kamina en Kitona, een Belgisch-gezinde wettige regering in Kinshasa, die in geval van nood beroep zou doen op Belgische militaire of financiële hulp, zag de toekomst er voor het kolonialisme rooskleurig uit."

Men wou de Belgische grondwet overplanten in Kongo. Bovendien dacht men aan een personele unie met de Koning als staatshoofd. Waarom werd dit laatste tenslotte overboord gegooid?

"De verrassende verkiezingsoverwinning van de nationalistische partijen in mei 1960 toonde aan dat de gok verloren was. Die 80 \% gematigden was een grondige vergissing, die niet te voorzien was. Volgens mij is dit te wijten aan de factor Lumumba. Lumumba is erin geslaagd in 
Pourquoi cette deuxième formule de décolonisation a-t-elle également été rejetée par la Belgique?

«A mon avis la Belgique s'était bien rendu compte qu'elle était obligée de décoloniser, mais elle voulait limiter cela à une indépendance juridique et empêcher que les intérêts économiques belges soient menacés par des influences étrangères, influences qui par le canal des Nations Unies auraient inévitablement pénétré le pays.

La préoccupation de préserver le plus possible les intérêts économiques belges et en même temps d'éviter à l'Etat belge les lourdes charges financières et militaires que le maintien de la colonie aurait entraînées, peut expliquer pourquoi finalement on a choisi la troisième solution : l'indépendance immédiate. "

\section{$\underline{\text { Le pari }}$}

«Au début de 1960, on produisait des statistiques selon lesquelles $80 \%$ des électeurs étaient des ruraux non-politisés qui probablement voteraient avec modération, ce qui mènerait à un parlement et à un gouvernement eux-mêmes modérés. Et le temps était trop court pour entreprendre une formation convenable de cadres ; ainsi le Congo Indépendant devrait, qu'il le veuille ou non, s'appuyer sur le système existant, sur les fonctionnaires, les juges et les officiers belges.

A juste titre, le gouvernement belge appelait cette politique 'le pari congolais', mais ce pari se révélera plus tard téméraire.

On ne doutait pas qu'on gagnerait ce pari. Avec des troupes belges dans les bases de Kamina et Kitona, un gouvernement légal pro-belge à Kinshasa, qui en cas de besoin ferait appel à l'aide militaire belge ou à l'aide financière, l'avenir du colonialisme paraissait souriant. »

On avait voulu transplanter la constitution belge au Congo. Par ailleurs, on avait cru à une union personnelle entre les deux pays avec le roi comme chef d'Etat. Pourquoi est-ce que cela a été rejeté?

«La surprenante victoire électorale des partis nationalistes en mai 1960 a fait voir que le pari était perdu. L'idée des $80 \%$ de modérés constituait une sérieuse erreur, mais l'évolution qui s'est produite n'était pas prévisible. Elle est due, d'après moi, à l'action de Lumumba. Lumumba a réussi en moins de trois mois à radicaliser fortement 
nauwelijks drie maanden tijd, zonder uitgebouwd partijapparaat en zonder aanzienlijke middelen het binnenland sterk te radicaliseren."

Ongeveer een maand na dle onafhankelijkheidsfeesten komt het Katanga probleem centraal te staan.

Waar berust de tegenstelling Lumumba-Tsombe op ?

Is dat politiek bepaald, etnisch, persoonlijk?

Ik denk politiek. Lumumba had een lange weg afgelegd. Rond de jaren 1956-57 was hij lid van de 'Cercle des Evolués de l'Amicale libérale'. In 1957 schreef hij 'Le Congo, terre d'avenir, est-il menacé ?', een boek dat in 1961 werd uitgegeven. Hij was toen vol bewondering voor de toenmalige minister van Koloniën, de liberaal Buisseret en erg ingenomen met diens integratiethesis over een 'Communauté belgo-congolaise'. Pas later werd hij een Kongolees nationalist en vijand van het kolonialisme, eerst onder invloed van Kasa-Vubu, vervolgens van Kwama Nkrumah. Het voortgezet contact met Nkrumah heeft van de nationalist Lumumba een jakobijns centralist en antitribalist gemaakt."

\section{Uitersten}

"Tshombe's gedachtengoed stond daar diametraal tegenover. Voor Lumumba was hij een tribalist en bondgenoot van buitenlandse economische machten (Union Minière !).

Tshombe was een ultra-decentralistisch autonomist, federalist Hij was federalist omdat hij heel het gewicht van Katanga achter zich had. De blanken in Katanga waren altijd al federalistisch, tegen Kinshasa gericht en zij stonden achter hem. Indirect werd hij gesteund door de U.M.H.K. [Union Minière du Haut Katanga] Bovendien behoorde hij tot de oude heersende families en die zochten ook van de onafhankelijkheid gebruik te maken om een groot stuk van hun vroegere positie terug te vinden.

Men zou kunnen zeggen dat ze twee zo'n extreme factoren waren dat ze moésten botsen."

Had men op de rondetafelconferentie reeds de indruk dat de politieke rollen al verdeeld waren tussen de drie hoofdfiguren van het Kongolees politiek toneel, Kasa-Vubu, Lumumba en Tshombe?

"Zeker niet. Geen van deze drie behoorde tot de, kandidaten die het vertrouwen of de voorkeur genoten van de Belgische 
l'intérieur du pays, et ce sans appareil partisan développé ni moyens financiers considérables. »

Environ un mois après les fêtes de l'indépendance, le problème du Katanga est à la une. Sur quoi repose l'opposition Lumumba - Tshombé ? Est-elle politique, éthique ou personnelle?

«Je la crois politique. Lumumba avait parcouru un long chemin. En 1956-1957, il était membre du 'Cercle des Evolués de l'Amicale libérale'. En 1957, il a écrit 'Le Congo, terre d'avenir, est-il menacé ?', un livre publié en 1961. Il était alors plein d'admiration pour le ministre des Colonies, le libéral Buisseret, et très satisfait de la thèse de celuici sur l'intégration dans une 'Communauté belgo-congolaise'. C'est plus tard, qu'il est devenu un nationaliste congolais et un ennemi du colonialisme, d'abord sous l'influence de Kasa-Vubu, ensuite sous celle de Kwame Nkrumah. Les relations suivies avec Nkrumah ont fait du nationaliste Lumumba un Jacobin centraliste et antitribaliste. »

\section{Les extrêmes}

«Tshombé avait des orientations absolument contraires. Aux yeux de Lumumba il était un tribaliste et un allié des pouvoirs économiques étrangers (Union Minière).

Tshombé était un autonomiste ultra-décentraliste, un fédéraliste. Il était fédéraliste parce qu'il pouvait compter sur toute la puissance du Katanga. Les blancs du Katanga étaient acquis au fédéralisme par opposition à Kinshasa et ils étaient derrière lui. Il était aussi soutenu indirectement par l'U.M.H.K [Union Minière du Haut Katanga]. En outre, il appartenait aux vieilles familles régnantes qui cherchaient à utiliser l'indépendance pour retrouver une grande partie de leur position antérieure.

On peut dire qu'il s'agissait de deux personnes aux positions tellement extrêmes et opposées qu'elles devaient nécessairement s'affronter. "

Avait-on l'impression lors de la conférence de la table ronde que les rôles politiques avaient déjà été partagés entre les trois héros du théâtre congolais, Kasa-Vubu, Lumumba et Tshombé?

« Surrement pas. Aucune de ces trois personnalités ne jouissait de la confiance et de la préférence du gouvernement belge. Ce n'est qu'après les élections de mai 1960, que la 
regering. Pas na de verkiezingen van mei 1960 lagen de kaarten duidelijker.

Op de rondetafelconferentie hield Tshombe contact met het 'Cartel' [fédéraliste] van partijen waartoe o.a. Abako, M.N.C. [Mouvement National Congolais, hier de M.N.C.Kalondji] P.S.A. [Parti Solidaire Africain], Abazi [Alliance des Banyanzi-Est de Banningville] en enkele kleinere groepen behoorden en die op het secretariaat van de MARZORATI-groep bijeenkwamen."

\section{Profeet}

"Tussen de rondetafelconferentie en de verkiezingen werd ik door Tshombe naar Elisabethstad geroepen voor overleg. Typisch Tshombe, voor de Afrikanen van toen was dat een uitzonderlijk ondernemend gebaar.

Tshombe : 'Luister ! Men zegt mij dat Lumumba een communist is, dat hij de meerderheid zal halen, dat ik mij beter kan losscheuren.

Ik antwoordde : 'Lumumba is geen communist. Hij heeft er trouwens de tijd niet voor om het te worden, van nu tot juni. De Sovjets kunnen Kongo niet komen inpalmen. En, wees gerust, hij zal niet de grote politieke sprong maken, de macht zal verdeeld zijn."

Hij liet mij toen een tekst zien, een soort proclamatie van de onafhankelijkheid van Katanga. Dat was in april. Na de verkiezingen van mei, een nieuw telegram. Ik ga weer naar Elisabethstad : 'Ge zijt mis over Lumumba. Ge zijt dus niet de profeet die ik dacht. Ik had dus gelijk en wij zullen nu de onafhankelijkheid uitroepen !'.

Ik heb hem toen aangeraden te onderhandelen met de twee hoofdfiguren en te proberen defensie en economische zaken of financiën in handen 'te krijgen. Dat heeft hij toen gedaan en in de eerste Kongolese regering zaten er twee ministers en een staatssecretaris (van defensie, want Lumumba hield het ministerschap van defensie voor zich om te kunnen beslissen over het inschakelen van de Belgische troepen) van zijn partij.

Pas een maand later, op 11 juli 1960, werd de secessie doorgevoerd, minstens 'objectief' beschermd door de Belgische troepen eenheden uit Kamina die de eenheden van het nationaal leger hadden ontwapend." 
distribution des cartes devint plus claire.

Pendant la conférence de la table ronde, Tshombé gardait le contact avec le 'Cartel' [Cartel fédéraliste] de partis auquel appartenaient en particulier l'Abako, le M.N.C. [Mouvement National Congolais, ici le M.N.C. - Kalondji], le P.S.A. [Parti Solidaire Africain], l'Abazi [Alliance des Banyanzi-Est de Banningville] ainsi que quelques petits groupes qui se réunissaient au secrétariat du groupe MARZORATI.»

\section{Prophète}

« Entre la conférence de la table ronde et les élections, Tshombé m'a demandé de venir à Elisabethville pour un entretien. C'était typique de la part de Tshombé. Pour les Africains d'alors, c'était un geste extrêmement entreprenant.

Tshombé: 'Ecoutez! On me raconte que Lumumba est un communiste, qu'il remportera la majorité et que je ferais mieux de me retirer.'

J'ai répondu : 'Lumumba n'est pas un communiste. De maintenant à juin, il n'a même pas le temps de le devenir. Les Soviétiques ne peuvent pas s'approprier le Congo. Soyez tranquille, il ne fera pas un grand bond politique, le pouvoir sera partagé.'

Il me fit voir un texte, une sorte de proclamation d'indépendance du Katanga. C'était en avril. Après les élections du mois de mai, j'ai reçu un nouveau télégramme. Je suis retourné à Elisabethville : 'Tu te trompes au sujet de Lumumba. Tu n'es donc pas le prophète que je croyais. J'avais donc raison et c'est nous maintenant qui allons proclamer l'indépendance!'

Je lui ai alors conseillé de négocier avec les deux personnes clés et d'essayer d'obtenir la défense et les affaires économiques ou les finances. C'est ce qu'il a fait. Dans le premier gouvernement congolais son parti était représenté par deux ministres et un secrétaire d'Etat à la Défense (Lumumba s'était octroyé la fonction de ministre de la Défense, ceci afin de pouvoir décider lui-même d'un appel aux troupes belges).

C'est seulement un mois plus tard, le 11 juillet 1960, que la sécession a été réalisée, avec la protection en tout cas 'objective' des troupes belges de Kamina, qui avaient désarmé les unités de l'armée nationale.» 
De Belgische overheid heeft altijd beweerd Kongo bijeen te willen houden. Anderzijds heeft zij toch de Katangese secessie gesteund. In hoeverre gebeurde dat officieel ?

"Ik denk dat de Belgische regering voor een voldongen feit werd gesteld, hoewel er te Brussel en in de koloniale administratie heel zeker 'conditionele voorstanders' voor de afscheiding van Katanga waren - wellicht tot in de schoot van de regering. Door 'conditioneel' versta ik dat zij de secessie slechts aanvaardden van het ogenblik af dat het bewind te Kinshasa, vanuit Belgisch standpunt onbetrouwbaar werd.

Wat hier ook van $\mathrm{zij}$, eens de secessie tot stand gebracht, werd zij door de Belgische regering actief en tot het uiterste gesteund en overeind gehouden, zowel door de aanwezigheid van de en pseudo-diplomatische missie ambassadeur Rotschild)-als door talrijke ambtenaren, technische coöperanten en militairen, de actieve technische steun van de Belgische Nationale Bank, enz.

In de schoot van de regering was graaf Harold D'Aspremont Lynden, eerst kabinetschef van premier Eyskens, later minister van Afrikaanse zaken, een actief en overtuigd 'Katangees'. Andere ministers waren dat niet.

In de koloniale zakenwereld heerste ook hier verdeeldheid over. Men kan dus niet veralgemenen. In de koloniale tijd dekte België het systeem van voordelen maar binnen dat systeem traden er toch vaak spanningen op en was het officieel gezag vaak een rem op al te grove exploitatie.

De overheid werd toch enigszins anders beïnvloed door haar achterban en zag misschien ook ietwat verder dan de zuiver particuliere belangen..."

Een boeiend punt. Materie voor nog vele gesprekken. Dank alvast voor dit beeld-van-binnenuit. 
Les autorités belges ont toujours juré vouloir garder le Congo réuni. D'autre part, elles ont toujours soutenu la sécession katangaise. Dans quelle mesure cette politique était-elle officielle?

« Je crois que le gouvernement belge a été mis devant le fait accompli, bien qu'à Bruxelles et dans l'administration coloniale il y avait sûrement des 'partisans conditionnels' de la sécession du Katanga - probablement même au sein du gouvernement. Je dis 'conditionnel' pour souligner qu'ils n'étaient partisans de la sécession que dans l'hypothèse où le gouvernement de Kinshasa, du point de vue belge, deviendrait non fiable.

Quoiqu'il en soit, lorsque la sécession a été proclamée, elle a été appuyée activement et jusqu'à l'extrême, par le gouvernement belge et puis elle a été maintenue debout, tant par la présence d'une pseudo-mission diplomatique (celle de l'ambassadeur Rothschild) que par celle de nombreux fonctionnaires, coopérants techniques et militaires, ainsi encore que par le soutien technique actif de la Banque nationale de Belgique, etc.

Au sein du gouvernement, le comte Harold d'Aspremont Lynden, qui avait été chef de cabinet du Premier ministre Eyskens, avant de devenir ministre des Affaires africaines, était un 'Katangais' actif et convaincu. Mais d'autres ministres ne l'étaient pas.

Dans le monde colonial des affaires il y avait également des points de vue différents. On ne peut donc pas généraliser. Dans la période coloniale, la Belgique contrôlait le système d'octroi des avantages, mais au sein de ce système il y avait souvent des tensions et l'autorité officielle pouvait dans un certain nombre de cas être un frein à une exploitation trop grossière.

Les autorités étaient dans une certaine mesure influencées par leur base, et aussi voyaient peut-être un peu plus loin que les intérêts particuliers. »

Un sujet passionnant. Il y a de la matière pour encore de nombreux entretiens. Entre-temps, merci pour cette vision de l'intérieur! 


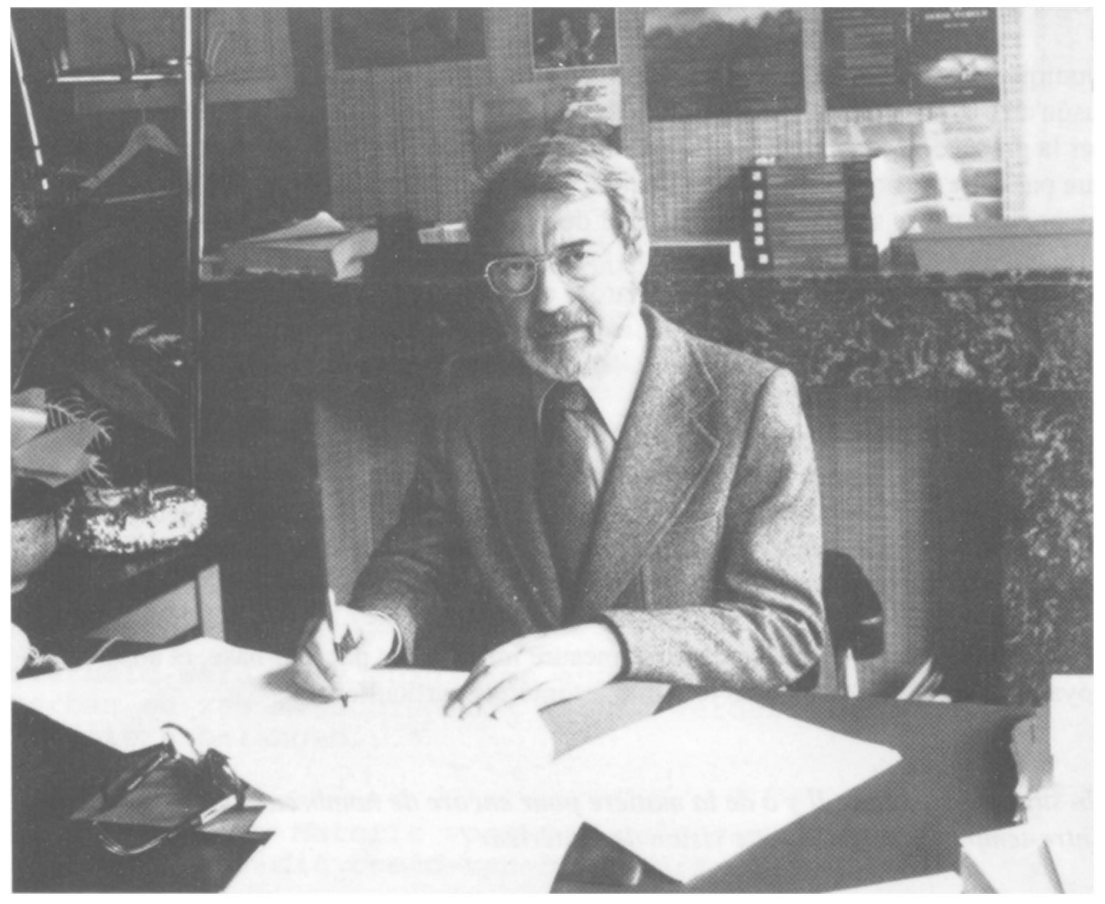

Professor A.A.J. Van Bilsen aan de Rijksuniversiteit Gent, 1978

Foto: DB 